\title{
Thyroid and colorectal cancer screening in acromegaly patients: should it be different from that in the general population?
}

\author{
Massimo Terzolo', Soraya Puglisi ${ }^{1}$, Giuseppe Reimondo ${ }^{1}$, Christina Dimopoulou ${ }^{2}$ and \\ Günter K Stalla ${ }^{2,3}$ \\ ${ }^{1}$ Azienda Ospedaliero Universitaria San Luigi Gonzaga, Department of Clinical and Biological Sciences, University of \\ Turin, Orbassano, Italy, ${ }^{2}$ Medicover Neuroendocrinology, Munich, Germany, and ${ }^{3}$ Medizinische Klinik und Poliklinik \\ IV der Ludwig-Maximilians-Universität München, Munich, Germany
}

\author{
Correspondence \\ should be addressed \\ to S Puglisi \\ Email
}

sorayapuglisi@yahoo.com

\begin{abstract}
The literature on an association between acromegaly and cancer is particularly abundant on either colorectal cancer or thyroid cancer, and an endless debate is ongoing whether patients with acromegaly should be submitted to specific oncology screening and surveillance protocols. The aim of the present work is to review the most recent data on the risk of either colorectal cancer or thyroid cancer in acromegaly and discuss the opportunity for specific screening in relation to the accepted procedures in the general population.
\end{abstract}

\section{Introduction}

Patients with acromegaly are exposed to a persistent excess of growth hormone (GH), which stimulates the synthesis of insulin-like growth factor-1 (IGF1) (1). Given that elevated levels of IGF1 inhibit apoptosis and promote cell proliferation in many tissues (2), it is biologically plausible to consider acromegalic patients as at increased risk of cancer. The role of GH and, in particular, IGF1 in the promotion and development of cancer is well established in preclinical models, and population-based studies have detected an association between IGF1 levels and cancer risk such as colorectal, thyroid, breast, and prostate cancer (3).

Whether cancer should be considered part of the clinical manifestations of acromegaly remains a matter of controversy $(4,5)$. There are several reasons that may confound interpretation of published research and account for the discrepancies of the results.

First, most studies may have insufficient statistical power to detect a moderate increase in risk for different cancer types and adjust for confounding factors $(6,7,8)$.
Second, studies used different methodological approaches and heterogeneous patient populations, such as sexspecific series $(9,10)$ or hospitalized patients $(9,11)$. Casecontrol studies may result in an overestimation of risk, due to their inherent limitations in the capture of events (i.e. ascertainment bias) and identification of matching controls (i.e. well-worried bias) (12). Population-based studies are theoretically more robust, but should have a nationwide dimension and availability of accurate cancer registry data (13). However, it should be taken into account that epidemiology of cancer is not uniform between countries and even between different regions of the same country, being influenced by lifestyle and the genetic background of the population, as well as by environmental factors (1).

Needless to say, the retrospective nature of the studies and the fact that some of them date back to more than 40 years ago make the issue even more challenging. The availability of a more effective, multi-modal treatment of acromegaly has expanded the life expectancy of patients, 
who may now live until the elder age when cancer incidence rises (14). Therefore, the clinical relevance of the association between acromegaly and cancer may be expected to increase in the future.

The literature on an association between acromegaly and cancer is particularly abundant on either colorectal cancer or thyroid cancer, and an endless debate is ongoing whether patients with acromegaly should be submitted to specific oncology screening and surveillance protocols. The aim of the present work is to review the most recent data on the risk of either colorectal or thyroid cancer in acromegaly and discuss the opportunity for specific screening in relation to the accepted procedures in the general population.

\section{For}

\section{Thyroid cancer}

\section{Screening in the general population}

Thyroid cancer screening is not recommended in asymptomatic adults at average risk due to: (i) the relative rarity of the tumor; (ii) the fact that treatment of early thyroid cancer does not seem to confer a better survival to treated patients than untreated ones; and (iii) the unchanged mortality rate from thyroid cancer despite its increased incidence in the last 10 years (15). In adults at increased risk because of previous exposure to ionizing radiation (especially in childhood), inherited genetic syndromes associated with thyroid cancer, or familial history of thyroid cancer, the American Thyroid Association (ATA) guidelines do not recommend for or against screening. As a matter of fact, there is no evidence that thyroid cancer screening is able to reduce morbidity and mortality, although it may lead to earlier diagnosis (15).

\section{Acromegaly and thyroid cancer: preclinical evidence}

The ATA guidelines do not include acromegaly in the list of conditions at increased risk of thyroid cancer; however, a wealth of experimental and epidemiological data supports this view.

Findings of several immunohistochemical studies confirmed the hypothesis of an IGF1-mediated mechanism of cancer promotion in thyroid cells. The first demonstration of the presence of IGF1 receptors in human thyroid cells dates back to 1989 by Yashiro et al. (16), who also showed that IGF1 binding in neoplastic tissues was significantly higher than in surrounding normal tissues. In the next years, studies demonstrated how the expression of IGF1 and IGF1 receptor was correlated with thyroid cancer aggressiveness $(17,18)$. Kim et al. (19) suggested that, in patients with acromegaly, a dominant role in the development of papillary thyroid cancer (PTC) could be played by a hyperactive GH-IGF1 axis, rather than the BRAFV600E mutation. The authors found that 15 out of 60 acromegalic patients (25\%) harbored a PTC and compared these patients to a control group of 16 non-acromegalic patients with PTC. The BRAFV600E mutation was present in only 1/11 (9.1\%) of the acromegalic patients compared to 10/16 (62.5\%) control patients $(P=0.007)$. In this study, uncontrolled GH-IGF1 secretion was significantly more frequent in the group of acromegalic patients with PTC $(60 \%)$ than in patients without $(28.9 \%)(P=0.030)$. Also, Aydın et al. (20) confirmed that BRAFV600E mutation does not play a causative role in the development of differentiated thyroid cancer (DTC) in acromegaly, as BRAFV600E mutation was found in $2 / 14(14.3 \%)$ acromegalic patients with DTC compared to $9 / 14(64.3 \%)$ non-acromegalic patients with DTC $(P=0.02)$. Recently, Keskin et al. (21) compared protein expressions via immunohistochemical staining in PTC of 13 acromegalic patients and 20 patients without acromegaly, reporting a similar expression of BRAF in the two groups, while IGF1 and Galectine 3 expression was significantly higher in the acromegaly group. Moreover, the 13 acromegalic patients with PTC had higher levels of GH and IGF1 than 300 acromegalic patients without (21).

\section{Acromegaly and thyroid cancer: clinical evidence}

This experimental evidence fits well with the epidemiological observation of a higher frequency of thyroid nodules and cancers in acromegaly patients compared to the general population. However, the incidence of thyroid cancer in patients with acromegaly varied considerably in studies done in different countries. In Italy, we evaluated the standard incidence ratios (SIRs) of different cancer types on a nationwide cohort of 1512 acromegalic patients and found a significantly increased incidence of thyroid cancer (SIR: 3.99; 95\% CI: 2.32-6.87, $P<0.001$ ) (5). Similar findings have been reported in other European studies $(11,22)$, whereas a recent North American study showed that the prevalence of thyroid cancer in acromegalic patients with thyroid nodules was similar to that reported in the general population with thyroid nodules (7-15\%) (23). This countryrelated variability could be related to different dietary 
iodine intake, which is known to have an influence on thyroid cancer risk, but also to a different use of thyroid ultrasonography in the general population.

Since proactive thyroid cancer screening with ultrasonography is tied with a greater number of diagnoses, it is conceivable that the elevated frequency of thyroid cancer in acromegalic patients could be due to enhanced use of diagnostic tests. However, a higher frequency of thyroid cancer in acromegalic patients has also been reported in South Korea, where an organized cancer-screening program had been implemented in 1999 that involves screening for asymptomatic thyroid cancer using ultrasound $(24,25)$. A nationwide survey on 3633 adults between 20 and 70 years of age reported that $23.3 \%$ of the participants underwent thyroid ultrasonography. The outcome of screening was that $70.7 \%$ of the tests were normal, while in $23.6 \%$ of subjects, thyroid nodules were detected and in $1.9 \%$ of subjects a thyroid cancer was diagnosed (25). In that country, a study on 60 acromegalic patients, who were evaluated with thyroid ultrasonography, reported that thyroid nodules were detected in $75.0 \%$ (45/60) of patients and thyroid cancer in $25.0 \%(15 / 60)$ of them (19). Despite the small sample size of the study, the difference with the general population is striking and cannot be accounted for a more intensive diagnostic testing in patients with acromegaly given that thyroid cancer screening is well-practiced in South Korea.

However, the issue of a different intensity of screening between the general population and acromegalic patients, which may introduce a possible bias in the detection of thyroid cancer, remains a matter of debate. This point has been raised in a meta-analysis and systematic review published in 2014 (26), in which the authors concluded that the amount of reliable papers, including controls groups and data on both benign and malignant thyroid nodular disease, is unsatisfactory. As a matter of fact, only 5 studies among the 22 initially selected were found to compare the prevalence of thyroid cancer and 3 studies the prevalence of benign thyroid lesions, in either acromegalic patients or sex- and age-matched control subjects. This meta-analysis showed an odds ratio (OR) of 7.9 (95\% CI: 2.8-22.0) for thyroid cancer and an OR of 3.6 (95\% CI: 1.8-7.4) for benign lesions in patients with acromegaly. Moreover, the relative risk (RR) of thyroid cancer in acromegalic patients with thyroid nodules was non-significantly higher (RR 3.2, 95\% CI: 0.5-20.1) than in non-acromegalic patients, when assessing the studies that included a concomitant control group. Interestingly, a higher prevalence of nodular goiter and thyroid cancer was found in more recent studies. The pooled prevalence of thyroid cancer was about 3\% in the studies published before 2008 and about 6\% in studies published since then. The same authors updated the metaanalysis in 2017 (27), confirming that the OR for thyroid cancer and for benign lesions was remarkably increased in patients with acromegaly $(4.1 ; 95 \%$ CI: $2.0-8.3$ and 3.3; 95\% CI: 2.1-5.4, respectively), while the RR for thyroid cancer was non-significantly increased compared with non-acromegalic subjects (2.3; 95\% CI: 0.9-6.1, $P=0.08$ ).

More recently, Dal et al. (28) performed a metaanalysis concerning different types of neoplasms in acromegalic patients, including thyroid cancer. Although the inclusion criteria were different compared to the previous meta-analysis (26), a significantly increased prevalence of thyroid cancer in patients with acromegaly was confirmed (pooled SIR=9.2; 95\% CI: 4.2-19.9). However, we still do not know whether thyroid tumors in patients exposed to a chronic excess of GH-IGF1 have a different (more aggressive) behavior.

\section{Recommendations for screening in patients with acromegaly}

For all the aforementioned considerations, it is our opinion that the recommendation of the Endocrine Society Guidelines (29) and the Acromegaly Consensus Group (30) of performing thyroid ultrasonography in case of palpable nodularity should be extended to all patients with acromegaly. The patients in whom thyroid nodules are detected at diagnosis should undergo follow-up surveillance.

The plain and uncontroversial evidence of an increased prevalence of benign nodular disease in acromegaly justifies this simple and cost-effective test, which is frequently performed as a point-of-care ultrasonography. Thyroid ultrasonography is particularly useful in patients with uncontrolled disease, since there is evidence that thyroid nodules may grow significantly in patients with active acromegaly $(31,32)$, and it is held that the risk of malignancy may be associated with an increase in nodule volume (33). The need of a close monitoring of thyroid nodules in acromegalic patients is in line with the ATA Guidelines that recommend fine-needle aspiration biopsy of any nodule that increases in size by more than $20 \%(15)$.

\section{Colorectal cancer}

Screening in the general population

In the average-risk population, including individuals of 50-75 years of age with no additional risk factors, the 
recommended screening for colorectal cancer is one of the following: fecal immunochemical testing every 2 years, colonoscopy every 10 years, or sigmoidoscopy every 10 years plus fecal immunochemical testing every 2 years (34). In fact, it has been demonstrated that colonoscopy screening with the removal of adenomas is an effective strategy for reducing colorectal cancer incidence and mortality (35). Screening procedures are different in above-average-risk population, as are individuals with family or personal history of colorectal cancer, long-standing history of inflammatory bowel disease or adenomatous polyps, and genetic syndromes such as familial adenomatous polyposis (34). Acromegaly is not cited as a condition associated with increased risk; however, experimental and epidemiological data support the view that exposure to chronic GH-IGF1 excess confers an increased risk of colorectal cancer.

\section{Acromegaly and colorectal cancer: preclinical evidence}

Since the fifties, it is known that elevated levels of serum GH-IGF1 promote the development of colon neoplasms $(36,37,38)$. Additional evidence has accumulated in the last decades on the role of IGF1 in colorectal tumorigenesis in acromegalic patients. Bogazzi et al. demonstrated that apoptosis was reduced in the colonic mucosa of patients with active acromegaly compared to patients in remission and controls, with an inverse relationship with serum IGF1. The same study showed that expression of PPAR gamma, a tumor suppressor gene involved in colonic tumorigenesis, was reduced in the colonic mucosa of patients with acromegaly (39). Moreover, it has been demonstrated that patients with active acromegaly have increased proliferation of colonic epithelial cells, as Ki-67 staining in biopsy samples was significantly higher compared to healthy controls. The same study showed that serum IGF1 levels were associated with increased proliferation in the superficial crypt cells (40). Zhang et al. reported that serum IGF1 and mRNA levels for mucosal IGF1 receptors (IGF1R) were significantly higher in patients with adenomatous or neoplastic polyps compared with healthy controls (41). Moreover, expression of IGF1, IGF1R and of their mRNA were higher in colorectal cancer than in colon adenoma and normal tissues (42). Interestingly, expression of IGF1 and IGF1R mRNA was associated with the degree of differentiation and metastatic spread of colorectal cancer and was also an independent prognostic factor (42). In a prospective study of 210 patients with colorectal cancer, a significant correlation between IGF1 expression and tumor size and depth of invasion was demonstrated (43).
In the last few years, studied shaped better the role of $\mathrm{GH}$ in colorectal tumorigenesis, demonstrating that $\mathrm{GH}$ suppresses the expression of p53 and p21 in colon cancer cells, whereas the administration of a GH-receptor antagonist (Pegvisomant) to acromegalic patients increases the expression of p53 and APC (adenomatous polyposis coli) (44). More recently, the same group demonstrated that, in colon cells, GH inhibited the DNA damage repair pathways, thus promoting chromosomal instability (45). Another study using cells with disrupted IGF-1R, to block IGF1 effect, showed that GH induces colon DNA damage independently of IGF1 (46). All these findings suggest that both IGF1 and GH may act within the cellular microenvironment in colorectal cancerpromoting neoplastic growth.

\section{Acromegaly and colorectal cancer: clinical evidence}

Preclinical findings are in line with clinical evidence from either epidemiological studies in the general population or cohort studies in patients with acromegaly.

Several studies in the background population suggested that adults with levels of serum IGF1 at the high end of the normal range have increased risk of colorectal cancer $(47,48,49)$. Conversely, elevated levels of IGF binding protein-3 (IGFBP-3) have been associated with a lower risk of cancer $(47,48)$, although the strength of the association is inferior (3). In acromegalic patients, however, GH excess increases serum IGF1 and, to a lesser extent, IGFBP-3; therefore, the IGF1/IGFBP-3 ratio steeply increases as $\mathrm{GH}$ levels raise $(50,51)$, and an elevated IGF1/IGFBP-3 ratio may lead to enhanced cancer risk in acromegaly $(47,52)$.

Rokkas et al. (53) performed a meta-analysis of colonoscopy studies in acromegaly done before December 2007 and analyzed 9 of 106 potentially eligible studies including 701 acromegalic patients and 1573 controls. The pooled results showed that acromegalic patients have a significantly increased risk of developing hyperplastic colon polyps (OR: 3.703; 95\% CI: 2.565-5.347), colon adenomas (OR: 2.537; 95\% CI: 1.914-3.264) and colon cancer (OR: 4.351; 95\% CI: 1.533-12.354). The metaanalysis included a multicentric Italian study on a cohort of 235 patients with acromegaly and 233 subjects with non-specific abdominal symptoms who served as controls (54). The most important colonoscopy findings were adenoma in 55 patients (23.4\%) and 34 control subjects (14.6\%) with OR 1.7 (95\% CI: 1.1-2.5) and colorectal cancer in 10 patients $(4.3 \%)$ and 2 controls $(0.9 \%)$ with OR 4.9 (95\% CI: 1.1-22.4). 
More recently, Dal et al. (28) performed a populationbased study and an accompanying meta-analysis on the risk of different types of cancer in patients with acromegaly. With both approaches, the risk of cancer was found to be slightly increased in acromegaly, with a pooled SIR for all cancers from meta-analysis of 1.5 (95\% CI: 1.2-1.8). For colorectal cancer, the SIR was 2.6 (95\% CI: 1.7-4.0). Considerable heterogeneity was found but no evidence of publication bias. There was no sex-related difference, while age-specific patterns were not reported.

The main findings of this study are in agreement with our nationwide survey reporting an overall SIR for cancer of 1.41 (95\% CI: 1.18-1.68) (5). For colorectal cancer, we found a SIR of 1.67 (95\% CI: 1.07-2.58); the risk of cancer was increased in either sex, and both age and family history were factors associated to all-type cancer risk. The number of patients submitted to proactive cancer screening was comparable between patients with and without cancer (5). The fact that acromegaly confers only a moderate increase in the risk of cancer may explain why some less-powered cohort studies have failed to document it (Fig. 1) (7, 8, 9, 10, 11, 28, 55, 56, 57, 58, 59, 60, 61, 62, $63,64,65,66,67,68,69,70,71,72,73,74,75,76,77)$.

Most studies failed to demonstrate any relationship between the activity of acromegaly and risk of colorectal cancer $(54,78)$. However, this does not argue against the hypothesis that GH and IGF1 are implicated in colorectal tumorigenesis, since a hormonal evaluation at a single point in time in the course of a long-lasting disease such as acromegaly cannot fully reflect the chronic exposure to GH and IGF1 excess. Interestingly, Dworakowska et al. (79) demonstrated that acromegalic patients with a normal baseline colonoscopy and persistently elevated IGF1 values had a 7.5 -fold risk of a subsequent adenoma, compared to those with a normal colonoscopy at the initial screening and controlled disease. Moreover, acromegalic patients with an initial adenoma had a 4.4- to 8.8-fold increased risk of developing a new adenoma at follow-up colonoscopy. These findings are in agreement with a previous study from our group that showed how the presence of a colonic neoplasm (adenoma or cancer) at the screening colonoscopy predicted finding new lesions at follow-up colonoscopy (54). Patients with colonic neoplasms at the repeat colonoscopy had increased IGF1 levels than patients without (54).

\section{Recommendations for screening in patients with acromegaly}

Given this premise, we believe that screening colonoscopy is justified in patients with acromegaly at the time of diagnosis. Colonoscopy should not be deferred in patients younger than 50 years, the age at which screening is recommended in the average-risk population. There is indeed evidence that the risk of colon neoplasms may be higher in younger patients when acromegaly is usually more aggressive (54).

There is substantial agreement between Endocrine Scientific Societies $(29,30,80,81)$ on the need of

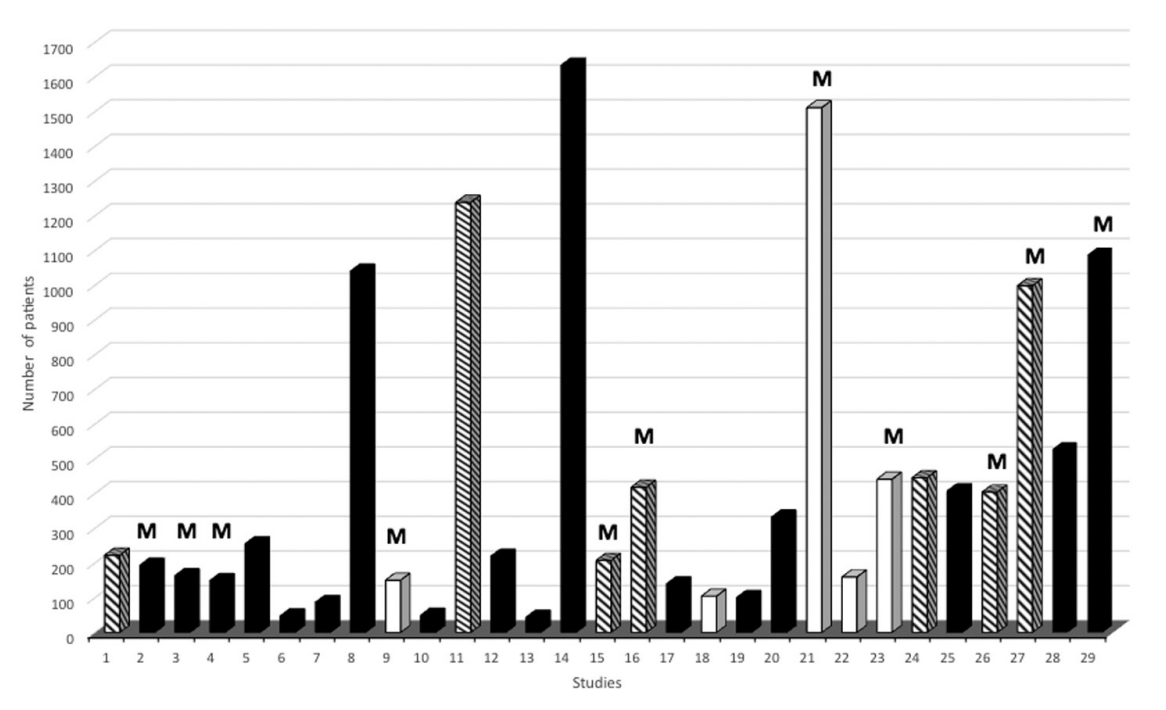

\section{Figure 1}

Sample size of the population-based studies on acromegaly and cancer. Black bars indicate studies showing a positive association between acromegaly and cancer, striped bars indicate negative studies, and white bars indicate studies that do not conclude whether an association is either present or not. Studies which focus on mortality only are marked by the letter $M$. The correspondence between the number of the study and references is as follows: 1 (55); 2 (56); 3 (10); 4 (57); 5 (58); 6 (59); 7 (60); 8 (9); 9 (61); 10 (62); 11 (63); 12 (64); 13 (65); 14 (11); 15 (66); 16 (67); 17 (68); 18 (69); 19 (70); 20 (71); 21 (72); 22 (73); 23 (74); 24 (7); 25 (8); 26 (75); 27 (76); 28 (28); 29 (77). 
colonoscopy at the time of diagnosis of acromegaly. The timeline of repeat colonoscopy varies in relation to the control of GH-IGF1 excess, and follow-up colonoscopy should be performed more frequently than in the general population when acromegaly remains active. Therefore, colonoscopy should be repeated every 5 years whenever a colonic adenoma is found at screening or acromegaly is not properly controlled. Conversely, surveillance colonoscopy is deemed every 10 years.

Since most colorectal cancers arise from adenomatous polyps, colonoscopy screening may lead to removing the premalignant lesions reducing the risk of either cancer development or cancer-related mortality (82). Given that acromegaly is a condition at increased risk of colorectal cancer, we do not see a role for alternative screening modalities that are less effective than colonoscopy. However, it should be considered that attaining an optimal visualization of the whole colon in acromegalic patients may be a demanding task, because of the frequent presence of dolichocolon and colonic diverticula (83). Moreover, due to the twisting of the colon in acromegalic patients, a rigorous bowel preparation and an experienced endoscopist are mandatory to limit the risk of missing small lesions.

In conclusion, patients with acromegaly deserve a more stringent surveillance than average-risk population, since colonoscopy should be repeated every 5 years in patients with active disease and/or previous evidence of colonic neoplasm, while only for patients with the controlled disease and negative colonoscopy $(54,79)$ the time interval of 10 years does apply as in average-risk population. Moreover, surveillance should be initiated in patients younger than 50 years (54), the age cut-off to recommend screening in average-risk population, and should be performed only with colonoscopy, differently from the general population in which the alternative of fecal immunochemical testing every 2 years, or sigmoidoscopy every 10 years plus fecal immunochemical testing every 2 years, is also indicated (34).

\section{Against}

Data regarding cancer incidence among acromegaly patients are inconsistent. A positive association between GH and IGF-1 excess with thyroid, colorectal and other types of cancer has been suggested. However, these associations rely mostly on small epidemiological surveys and circumstantial evidence; large-scale epidemiological studies are lacking $(84,85)$. It has also been hypothesized that acromegaly, independent of hormonal secretion, is a disease that brings with it genetic and/or epigenetic alterations predisposing to neoplasia (13). In parallel literature, GH replacement therapy has been associated with increased cancer risk/tumour recurrence in children with previously treated malignancies; however, this has not been confirmed so far (12).

In order to identify published studies on the risk of cancer in acromegaly and to be able to provide an overview of the controversies surrounding this topic, we searched the PubMed database for publications in English from the last two decades (2000-2019). Although patients with acromegaly have a 2 - to 2.5 -fold increased mortality rate - predominantly due to non-cancer-related reasons - an accurate assessment of the true incidence of cancer in this group of patients remains ambiguous (86). In two larger series from the United Kingdom (63) and Germany (7), which have assessed the overall cancer rate in acromegaly in comparison with that in the general population, estimated SIR for several types of malignancies was lower or not different from the general population. Moreover, in a recent review by Tirosh et al., the authors state that thyroid micro-carcinomas are probably over-diagnosed among acromegalic patients, whereas there is no sufficient data to suggest that colon cancer risk is higher in acromegaly compared to that of the general population (87). Regarding mortality, Dal et al. conducted a nationwide cohort study from 1978 to 2010 including 529 acromegaly cases in Denmark; whereas overall mortality was elevated in acromegaly (SIR 1.3; 95\% CI: 1.1-1.6), cancer-specific mortality was not (28).

Although some data suggest that overall cancer risk might be slightly elevated in acromegaly compared to the general population, numerous potential sources of bias need to be discussed (28). Selection or sample bias is suggested by the fact that the elevated overall cancer incidence risk is more pronounced in single-center studies and lower when studies with less than ten cases are excluded. Additionally, we have to take into account that patient populations in single centers might represent difficult cases with previous treatment failure and increased comorbidity. It is could also be the case that the comparison group in single-center studies derives from screening programs, which poses the risk of healthyuser bias; this is of particular relevance in the context of colorectal cancer, for which screening programs are available (28). Surveillance bias or diagnostic workup bias risk can be reduced by excluding cancer cases detected within the first year after diagnosis of acromegaly. 


\section{Thyroid cancer}

\section{No increased prevalence}

Thyroid volume, evaluated by ultrasonography, is known to be higher in acromegaly and correlates to the estimated duration of the disease (88). While simple and multinodular goiters are more common among acromegalics, reports of thyroid carcinoma are rare and its true incidence remains unclear. Increased cancer rates in acromegaly are possibly due to increased plasma circulating levels of IGF-I, which is known to promote cellular growth (89).

The exact prevalence of benign and malignant nodular thyroid disease in patients with acromegaly is not known. Numerous studies have reported an increasing incidence of thyroid cancer in the last decade with a prevalence ranging from $5.6 \%$ up to $11.8 \%(73,90,91)$. However, this was not the case in all studies. In a meta-analysis of the literature regarding cancer incidence in patients with acromegaly by Dal, no significant difference was detected in thyroid cancer incidence between multicenter studies (pooled SIR = 7.6; 95\% CI: 2.4-24.5) and population-based studies (pooled SIR $=8.2$; 95\% CI: 3.6-18.7); only two single-center studies evaluated thyroid cancer incidence (28). In the largest - to our knowledge - study in this issue performed in Western European countries in the last decade, Gasperi et al. reported only a slightly increased prevalence of thyroid carcinoma than in the general population (3/258 patients) (88). The second largest study by Reverter et al. found a $2.4 \%$ rate of thyroid malignancy in a series of 123 acromegalic patients, which was lower than previously reported and anticipated (92).

\section{Sources of bias}

Numbers should be interpreted, taking into account epidemiological data from specific geographical regions, since we know that reported thyroid cancer incidence and prevalence varies considerably in different registries (93, 94). Differences regarding cancer incidence may be due to geographical, ethnic or environmental reasons, such as iodine intake or the prevalence of thyroid autoimmunity (92). In a recent meta-analysis and systematic review by Wollinski et al., the authors underline that reliable papers including control groups and data both on the prevalence of thyroid nodular disease and thyroid cancer are rather unsatisfactory (26). We should also keep in mind that the number of control subjects is adequate to make a conclusion about thyroid volume and goiter prevalence, but could be insufficient for detection of thyroid malignancy (92). Additionally, surveillance bias is of particular concern for thyroid cancer, since thyroid volume is enlarged in acromegaly, which may lead to a more frequent use of ultrasonography and subsequent overdiagnosis of occult thyroid cancer (95).

\section{Thyroid cancer screening}

Although thyroid malignancy is supposed to be one of the most commonly found cancers in acromegaly, the majority of guidelines do not mention it. The exception is the report from the Endocrine Society, stating that thyroid ultrasound should be offered to acromegalic patients with a palpable thyroid nodule (29). Other authors also consider it rational to perform periodic ultrasonographic evaluation in acromegaly, followed by fine-needle aspiration biopsies of suspect nodules (96). This is also the proposal of Siegel et al. who suggest careful monitoring of goiter and thyroid nodules, including fine-needle aspiration of nodules that are $1 \mathrm{~cm}$ or larger in acromegalic patients with persistently elevated IGF-I levels (89). In the end, this does not deviate from our common practice in the general, non-acromegalic population. No evidence exists that an aggressive and systematic approach to detect small, asymptomatic, low-risk, thyroid malignant nodules could affect mortality rates in acromegaly, while it could, in fact, be accompanied by unnecessary morbidity and poorer quality of life (4). This was confirmed by a recent retrospective chart review performed between 2006 and 2015 at the University of California, which revealed no benefit of dedicated thyroid nodule screening in patients newly diagnosed with acromegaly, since the prevalence of thyroid cancer in acromegalic patients and coexisting thyroid nodules was no different to that reported in the general US population with thyroid nodules (7-15\%) (23).

\section{Colorectal cancer}

\section{No increased prevalence}

Whether the incidence of colorectal cancer is increased in acromegaly remains a matter of debate in numerous publications. Two of the more recently published population-based studies did not find any excess risk of colorectal cancer in acromegaly $(6,7)$. In detail, the analysis from the German Acromegaly Registry $(n=446)$ showed a slightly - but not significantly lower - overall cancer incidence than in the general population $(\mathrm{SIR}=0.75 ; 95 \% \mathrm{CI}: 0.55-1.00 ; P=0.051)$ and was not significantly higher for colorectal, thyroid or other types of cancer. There was not a significant dependence on 
normal vs elevated IGF-1 $(P=0.87)$, radiation therapy $(P=0.45)$, disease duration $(P=0.96)$, age at diagnosis $(P=0.15)$, or during a period of high GH and IGF-1 from 8 years before to 2 years after diagnosis of acromegaly $(P=0.41)(7)$.

A retrospective, observational, non-interventional and cross-sectional analysis of 146 acromegalic patients in Padua, Italy, revealed an increased general risk for polyps and adenomatous polyps in acromegaly compared to the control population (odds ratio (OR): 1.33 and 1.16, respectively), but no cancerous polyps (97). Increased fasting insulin levels seem to be associated with an 8.6to 14.8-fold increased risk of presenting with colonic adenomas (98). In an Italian, multicenter, cross-sectional study, patients with acromegaly $(n=235)$ carried only a moderate increase in the risk of colonic carcinoma occurring at a younger age than in the general population (OR: 4.9; range: 1.1-22.4) compared to patients with nonspecific abdominal compliants (54).

The question as to whether the increased risk of colorectal cancers in acromegaly results in increased colorectal cancer-specific mortality in this group remains unanswered. Lois et al. concluded that although initial studies suggested an increased overall cancer-related mortality in acromegaly, this has not been supported by further studies (99). In the largest meta-analysis of colorectal neoplasia in acromegaly published in 2008, Rokkas et al. concluded that an overall cancer mortality risk was significantly greater only in the subgroup of patients with uncontrolled acromegaly (53).

\section{Sources of bias}

Although a number of studies suggest an increased prevalence of colorectal cancer in acromegaly, potential sources of bias need to be addressed. Most of the studies are too small to adjust for confounding factors, for example, sex, age and conclusions may rely on inappropriate control groups. Renehan et al. state that colonoscopybased studies of adenoma prevalence rates in acromegalic patients are misleading and often overestimated (100). This is attributed to the fact that no ideal control population for such studies exists and, therefore, the choice of controls is often inappropriate. The authors believe that population-based studies on colorectal cancer risk are more consistent; a meta-analysis estimated a pooled risk ratio of 2.04 (95\% CI: 1.32-3.14) (100). From a clinical point of view, it seems reasonable to perform colonoscopic screening at approximately 55 years of age, but potential risks and benefits should be weighed (101).
Renehan et al. further believe that risk assessment regarding acromegaly and colorectal cancer should rely on population-based studies, since disease prevalence is underestimated and there are major problems arising from lack of matched age-sex comparisons, the variability in colonoscopy completion rates, and the healthy-user factor in screened controls when comparing with published series of screened asymptomatic non-acromegalic patients (102). We should not forget that colonoscopy is an invasive and potentially harmful investigation and that an aggressive screening strategy may be associated with escalating morbidity and mortality, although potential benefits seem modest (102).

\section{Colorectal cancer screening}

Current guidelines for colorectal cancer screening vary according to cancer risk. Patients with hereditary syndromes are considered at 'very high risk' for colorectal cancer and are known to profit from frequent screening since colorectal cancer deaths are reduced. Individuals with a positive family history are considered to be at 'high risk' and early colonoscopic screening with regular surveillance is recommended. In 'average-risk' individuals, screening colonoscopy is proposed at the age of 50 according to the US guidelines (UK guidelines are less specific), while 'moderate risk' are those with an increasingly recognized, increased risk, but to a modest extent. Acromegaly seems to fall into this category, which is unfortunately not mentioned by either the US or the UK guidelines (102).

The majority of colon cancers develop as a result of a multistep malignant transformation of benign adenomatous colonic polyps, which takes about 10-15 years in non-acromegalic individuals. A wide range of predisposing factors such as diet, obesity, diabetes, and smoking as well as genetic and epigenetic mechanisms have been proposed (86). In order to be able to determine optimal colonoscopy screening in acromegalic patients, we should first identify acromegalic patients who are at risk of developing colonic adenomas. In a prospective study up to 5 years of 79 patients with active acromegaly, Bogazzi et al. suggest that the first colonoscopy helps to identify patients at high risk of developing colonic adenomas. If colonic adenomas are not initially present, it is rather unlikely that they develop thereafter, independently of the metabolic control of the disease. On the other hand, new lesions are frequent and multiple in patients who already have colonic adenomas at baseline, particularly in the case of uncontrolled acromegaly (103). 
The optimum frequency with which acromegalic patients should undergo colonoscopic screening again remains unclear. In a retrospective study by Dworakowska et al., patients treated at the center underwent at least one up to four surveillance colonoscopies. Repeated colonoscopic screening showed a high prevalence of new adenomatous and hyperplastic colonic polyps, dependent on both the occurrence of previous polyps and elevated IGF1 levels (79).

Current guidelines regarding regular colorectal cancer screening in acromegaly are controversial and are based on a variety of sources: the Acromegaly Consensus Group (ACG) guidelines in 2009, the British Society of Gastroenterology (BSG) in 2010, the American Association of Clinical Endocrinologists (AACE) in 2011, the Pituitary Society in 2013 and the Endocrine Society in 2014.

In the most recent guideline by the Endocrine Society (29), screening colonoscopy at diagnosis for all acromegalic patients is suggested, but only supported by weak, low-quality evidence. On the other hand, there is no reason for not performing it in patients with the first diagnosis of acromegaly over 50 years. It is known that adenoma excision at this age reduces colorectal cancer rates in average-risk individuals, while the risk in acromegalic patients seems to be just above the threshold for non-acromegalic individuals. In patients with the first diagnosis of acromegaly between 40 and 50 years of age, the decision should rely on cancer epidemiology and presence of predisposing factors, which is in the end no different than our common practice in the general population. In case that the skill of endoscopic team is questionable, other safer screening procedures such as computed tomographic colonography should be considered. Follow-up for acromegalic patients with a normal initial colonoscopy and controlled disease is comparable to that of the general population. If a polyp is detected in the first examination, the patient should undergo the second colonoscopy within 3-5 years, depending on the number, size and histology of the resected lesions. An interval of about 5 years seems reasonable, but remains debated, for patients with a normal initial colonoscopy and persistently elevated GH and IGF1 levels.

\section{Special issues regarding colonoscopic screening}

In acromegaly, several practical issues such as increased length of the colon (mainly the sigmoid) and increased circumference might influence colonoscopy success. Additionally, colonic transit times are twice longer than in normal individuals and therefore standard bowel preparation is often not enough. The procedure lasts much longer due to the colonic length and circumference, which means that the study should be ideally offered by an experienced examiner (86). There is general agreement that further studies are needed in order to enlighten optimal technical aspects of colonoscopy in acromegaly. Specific recommendations for large bowel endoscopic screening have been proposed (99).

The rare incidence of acromegaly means that assessment of the cost-benefit ratio is difficult. Cairns et al. report the example of the UK, comprising around 2500 patients with acromegaly, of whom about 2000 are aged 40 years or over. According to current data, about one fourth (500 patients) will have an adenoma and will be offered to be screened every 3 years, while the rest will be offered colorectal screening every 5-10 years. In conclusion, the number of extra examinations in each center due to acromegaly is rather small (104).

\section{Concluding remarks}

The question of whether acromegalic patients should undergo more extensive/frequent cancer screening has been debated long and passionately. Although current literature proposes a slightly elevated overall risk of cancer in acromegaly, at the moment, growth hormone excess in humans does not seem to present a serious cancer risk. Perhaps, the answer to embrace the different views and to preserve an optimal risk/benefit approach is on 'the middle way'. Among clinical endocrinologists, Melmed adopts a rather moderate position regarding malignancy risk in acromegaly. He states that 15\% of deaths in acromegaly are attributable to malignancies, which is lower than expected in the general population. Uncontrolled acromegaly may be linked to more aggressive neoplasms with potentially increased cancerassociated morbidity and mortality, but no clear evidence for enhanced de novo cancer initiation in acromegaly exists so far (105).

There are many problems and limitations in quantifying the risk of cancer in patients harboring a rare disease. Most studies include small numbers of individuals, with no statistical power to adjust the data for confounding factors, such as age and gender. The comparison between older and more recent series is challenging, as both cancer incidence in the general population and life expectancy in patients with acromegaly have dramatically changed over the past few decades, influencing the prevalence of disease-associated morbidities. In addition, populationbased cancer registries and epidemiology may differ 
from site to site. Finally, the heterogeneity of control populations used presents another source of bias (4).

In conclusion, at present, there is insufficient data to support an intensive thyroid or colorectal cancer screening in acromegaly. Patients with acromegaly should undergo regular screening with hormonal and ultrasound evaluation of the thyroid and fine-needle aspiration biopsy when required, comparable to that in the general population. Early colonoscopic screening and subsequent regular surveillance above that of the normal population cannot be supported by the evidence currently available. Rationale, together with potential risk and benefits, should be weighed. The increased risk for cancer is modest and the potential risk of invasional screening techniques considerable. Current guidelines may have to be revised before forcing physicians into a not evidence-based screening practice (106).

\section{Declaration of interest}

The authors declare that there is no conflict of interest that could be perceived as prejudicing the impartiality of this article.

\section{Funding}

This work did not receive any specific grant from any funding agency in the public, commercial, or not-for-profit sector.

\section{References}

1 Melmed S. Medical progress: acromegaly. New England Journal of Medicine 2006355 2558-2573. (https://doi.org/10.1056/ NEJMra062453)

2 O'Reilly KE, Rojo F, She QB, Solit D, Mills GB, Smith D, Lane H, Hofmann F, Hicklin DJ, Ludwig DL et al. mTOR inhibition induces upstream receptor tyrosine kinase signaling and activates Akt. Cancer Research 200666 1500-1508. (https://doi.org/10.1158/0008-5472. CAN-05-2925)

3 Renehan AG, Zwahlen M, Minder C, O'Dwyer ST, Shalet SM \& Egger M. Insulin-like growth factor (IGF)-I, IGF binding protein-3, and cancer risk: systematic review and meta-regression analysis. Lancet 2004363 1346-1353. (https://doi.org/10.1016/S01406736(04)16044-3)

4 Boguszewski CL \& Ayuk J. MANAGEMENT OF ENDOCRINE DISEASE: Acromegaly and cancer: an old debate revisited. European Journal of Endocrinology 2016175 R147-R156. (https://doi.org/10.1530/EJE-160178)

5 Terzolo M, Reimondo G, Berchialla P, Ferrante E, Malchiodi E, De Marinis L, Pivonello R, Grottoli S, Losa M, Cannavo S et al. Acromegaly is associated with increased cancer risk: a survey in Italy. Endocrine-Related Cancer 201724 495-504. (https://doi.org/10.1530/ ERC-16-0553)

6 Kauppinen-Makelin R, Sane T, Valimaki MJ, Markkanen H, Niskanen L, Ebeling T, Jaatinen P, Juonala M, Finnish Acromegaly Study Group \& Pukkala E. Increased cancer incidence in acromegaly - a nationwide survey. Clinical Endocrinology 201072 278-279. (https://doi.org/10.1111/j.1365-2265.2009.03619.x)

7 Petroff D, Tonjes A, Grussendorf M, Droste M, Dimopoulou C, Stalla G, Jaursch-Hancke C, Mai M, Schopohl J \& Schofl C. The incidence of cancer Among acromegaly patients: results from the German Acromegaly Registry. Journal of Clinical Endocrinology and Metabolism 2015100 3894-3902. (https://doi.org/10.1210/jc.20152372)

8 Cheng S, Gomez K, Serri O, Chik C \& Ezzat S. The role of diabetes in acromegaly associated neoplasia. PLOS ONE 201510 e0127276. (https://doi.org/10.1371/journal.pone.0127276)

9 Ron E, Gridley G, Hrubec Z, Page W, Arora S \& Fraumeni Jr JF. Acromegaly and gastrointestinal cancer. Cancer 199168 1673-1677. (https://doi.org/10.1002/1097-0142(19911015)68:8<1673::aidcncr2820680802>3.0.co;2-0)

10 Alexander L, Appleton D, Hall R, Ross WM \& Wilkinson R. Epidemiology of acromegaly in the Newcastle region. Clinical Endocrinology 198012 71-79. (https://doi. org/10.1111/j.1365-2265.1980.tb03135.x)

11 Baris D, Gridley G, Ron E, Weiderpass E, Mellemkjaer L, Ekbom A, Olsen JH, Baron JA \& Fraumeni JF. Acromegaly and cancer risk: a cohort study in Sweden and Denmark. Cancer Causes and Control 200213 395-400. (https://doi.org/10.1023/a:1015713732717)

12 Renehan AG \& Brennan BM. Acromegaly, growth hormone and cancer risk. Best Practice and Research: Clinical Endocrinology and Metabolism 200822 639-657. (https://doi.org/10.1016/j. beem.2008.08.011)

13 Loeper S \& Ezzat S. Acromegaly: re-thinking the cancer risk. Reviews in Endocrine and Metabolic Disorders 20089 41-58. (https://doi. org/10.1007/s11154-007-9063-z)

14 Gadelha MR, Kasuki L, Lim DST \& Fleseriu M. Systemic complications of acromegaly and the impact of the current treatment landscape: an update. Endocrine Reviews 201940 268-332. (https:// doi.org/10.1210/er.2018-00115)

15 Haugen BR, Alexander EK, Bible KC, Doherty GM, Mandel SJ, Nikiforov YE, Pacini F, Randolph GW, Sawka AM, Schlumberger M et al. 2015 American Thyroid Association management guidelines for adult patients with thyroid nodules and differentiated thyroid cancer: the American Thyroid Association Guidelines Task Force on thyroid nodules and differentiated thyroid cancer. Thyroid 201626 1-133. (https://doi.org/10.1089/thy.2015.0020)

16 Yashiro T, Ohba Y, Murakami H, Obara T, Tsushima T, Fujimoto Y, Shizume K \& Ito K. Expression of insulin-like growth factor receptors in primary human thyroid neoplasms. Acta Endocrinologica 1989121 112-120. (https://doi.org/10.1530/ acta.0.1210112)

17 Maiorano E, Ciampolillo A, Viale G, Maisonneuve P, Ambrosi A, Triggiani V, Marra E \& Perlino E. Insulin-like growth factor 1 expression in thyroid tumors. Applied Immunohistochemistry and Molecular Morphology 20008 110-119. (https://doi. org/10.1097/00129039-200006000-00005)

18 Gydee H, O'Neill JT, Patel A, Bauer AJ, Tuttle RM \& Francis GL. Differentiated thyroid carcinomas from children and adolescents express IGF-I and the IGF-I receptor (IGF-I-R). Cancers with the most intense IGF-I-R expression may be more aggressive. Pediatric Research 200455 709-715. (https://doi.org/10.1203/01. PDR.0000111282.98401.93)

19 Kim HK, Lee JS, Park MH, Cho JS, Yoon JH, Kim SJ \& Kang HC. Tumorigenesis of papillary thyroid cancer is not BRAF-dependent in patients with acromegaly. PLOS ONE 20149 e110241. (https://doi. org/10.1371/journal.pone.0110241)

20 Aydin K, Aydin C, Dagdelen S, Tezel GG \& Erbas T. Genetic alterations in differentiated thyroid cancer patients with acromegaly. Experimental and Clinical Endocrinology and Diabetes 2016124 198-202. (https://doi.org/10.1055/s-0035-1565061)

21 Keskin FE, Ozkaya HM, Ferahman S, Haliloglu O, Karatas A, Aksoy F \& Kadioglu P. The role of different molecular markers in papillary thyroid cancer patients with acromegaly. Experimental and Clinical Endocrinology and Diabetes 2019127 437-444. (https://doi. org/10.1055/a-0629-9223) 
22 Wolinski K, Stangierski A, Dyrda K, Nowicka K, Pelka M, Iqbal A, Car A, Lazizi M, Bednarek N, Czarnywojtek A et al. Risk of malignant neoplasms in acromegaly: a case-control study. Journal of Endocrinological Investigation 201740 319-322. (https://doi. org/10.1007/s40618-016-0565-y)

23 Lai NB, Garg D, Heaney AP, Bergsneider M \& Leung AM. No benefit of dedicated thyroid nodule screening in patients WITH acromegaly. Endocrine Practice 202026 16-21. (https://doi.org/10.4158/EP-20190254)

24 Ahn HS, Kim HJ \& Welch HG. Korea's thyroid-cancer 'epidemic' screening and overdiagnosis. New England Journal of Medicine 2014 371 1765-1767. (https://doi.org/10.1056/NEJMp1409841)

25 Shin S, Park SE, Kim SY, Hyun MK, Kim SW, Kwon JW, Kim Y, Kim WB, Na DG, Park HA et al. Effectiveness of ultrasonographic screening for thyroid cancer: round-table conference in the National Evidence-Based Healthcare Collaborating Agency (NECA) in conjunction with the Korean Thyroid Association. Asian Pacific Journal of Cancer Prevention 201415 5107-5110. (https://doi. org/10.7314/apjcp.2014.15.12.5107)

26 Wolinski K, Czarnywojtek A \& Ruchala M. Risk of thyroid nodular disease and thyroid cancer in patients with acromegaly - metaanalysis and systematic review. PLoS ONE 20149 e88787. (https:// doi.org/10.1371/journal.pone.0088787)

27 Woliński K, Stangierski A, Gurgul E, Bromińska B, Czarnywojtek A, Lodyga M \& Ruchała M. Thyroid lesions in patients with acromegaly - case-control study and update to the meta-analysis. Endokrynologia Polska 201768 2-6. (https://doi.org/10.5603/EP.2017.0001)

28 Dal J, Leisner MZ, Hermansen K, Farkas DK, Bengtsen M, Kistorp C, Nielsen EH, Andersen M, Feldt-Rasmussen U, Dekkers OM et al. Cancer incidence in patients with acromegaly: a cohort study and meta-analysis of the literature. Journal of Clinical Endocrinology and Metabolism 2018103 2182-2188. (https://doi.org/10.1210/jc.2017. 02457)

29 Katznelson L, Laws ER, Melmed S, Molitch ME, Murad MH, Utz A, Wass JA \& Society E. Acromegaly: an endocrine society clinical practice guideline. Journal of Clinical Endocrinology and Metabolism 201499 3933-3951. (https://doi.org/10.1210/jc.2014-2700)

30 Giustina A, Barkan A, Beckers A, Biermasz N, Biller BMK, Boguszewski C, Bolanowski M, Bonert V, Bronstein MD, Casanueva FF et al. A consensus on the diagnosis and treatment of acromegaly comorbidities: an update. Journal of Clinical Endocrinology and Metabolism 2020 105. (https://doi.org/10.1210/clinem/dgz096)

31 Kan S, Kizilgul M, Celik B, Beysel S, Caliskan M, Apaydin M, Ucan B \& Cakal E. The effect of disease activity on thyroid nodules in patients with acromegaly. Endocrine Journal 201966 301-307. (https://doi.org/10.1507/endocrj.EJ18-0502)

32 Dogansen SC, Salmaslioglu A, Yalin GY, Tanrikulu S \& Yarman S. Evaluation of the natural course of thyroid nodules in patients with acromegaly. Pituitary 201922 29-36. (https://doi.org/10.1007/ s11102-018-0923-1)

33 Angell TE, Vyas CM, Medici M, Wang Z, Barletta JA, Benson CB, Cibas ES, Cho NL, Doherty GM, Doubilet PM et al. Differential Growth rates of benign vs. malignant thyroid nodules. Journal of Clinical Endocrinology and Metabolism 2017102 4642-4647. (https:// doi.org/10.1210/jc.2017-01832)

34 Qaseem A, Crandall CJ, Mustafa RA, Hicks LA, Wilt TJ \& Clinical Guidelines Committee of the American College of Physicians. Screening for colorectal cancer in asymptomatic average-risk adults: a guidance statement from the American College of Physicians. Annals of Internal Medicine 2019171 643-654. (https://doi.org/10.7326/M190642)

35 Winawer SJ, Zauber AG, Ho MN, O’Brien MJ, Gottlieb LS, Sternberg SS, Waye JD, Schapiro M, Bond JH \& Panish JF. Prevention of colorectal cancer by colonoscopic polypectomy. The National Polyp Study Workgroup. New England Journal of Medicine 1993329 1977-1981. (https://doi.org/10.1056/NEJM199312303292701)
36 MOON HD, SIMPSON ME, LI CH \& EVANS HM. Neoplasms in rats treated with pituitary growth hormone; pulmonary and lymphatic tissues. Cancer Research 195010 297-308.

37 Pollak MN, Polychronakos C, Yousefi S \& Richard M. Characterization of insulin-like growth factor I (IGF-I) receptors of human breast cancer cells. Biochemical and Biophysical Research Communications 1988154 326-331. (https://doi.org/10.1016/0006$291 x(88) 90688-2)$

38 Cats A, Dullaart RP, Kleibeuker JH, Kuipers F, Sluiter WJ, Hardonk MJ $\&$ de Vries EG. Increased epithelial cell proliferation in the colon of patients with acromegaly. Cancer Research 199656 523-526.

39 Bogazzi F, Russo D, Locci MT, Chifenti B, Ultimieri F, Raggi F, Cosci C, Sardella C, Costa A, Gasperi M et al. Apoptosis is reduced in the colonic mucosa of patients with acromegaly. Clinical Endocrinology 200563 683-688. (https://doi.org/10.1111/j.13652265.2005.02405.x)

40 Dutta P, Bhansali A, Vaiphei K, Dutta U, Ravi Kumar P, Masoodi S, Mukherjee KK, Varma A \& Kochhar R. Colonic neoplasia in acromegaly: increased proliferation or deceased apoptosis? Pituitary 201215 166-173. (https://doi.org/10.1007/s11102-011-0300-9)

41 Zhang R, Xu GL, Li Y, He LJ, Chen LM, Wang GB, Lin SY, Luo GY, Gao XY \& Shan HB. The role of insulin-like growth factor 1 and its receptor in the formation and development of colorectal carcinoma. Journal of International Medical Research 201341 1228-1235. (https:// doi.org/10.1177/0300060513487631)

42 Han L, Zhang GF, Cheng YH \& Zhao QC. Correlations of insulin-like growth factor I and insulin-like growth factor I receptor with the clinicopathological features and prognosis of patients with colon cancer. Japanese Journal of Clinical Oncology 201646 1127-1134. (https://doi.org/10.1093/jjco/hyw137)

43 Shiratsuchi I, Akagi Y, Kawahara A, Kinugasa T, Romeo K, Yoshida T, Ryu Y, Gotanda Y, Kage M \& Shirouzu K. Expression of IGF-1 and IGF-1R and their relation to clinicopathological factors in colorectal cancer. Anticancer Research 201131 2541-2545.

44 Chesnokova V, Zonis S, Zhou C, Recouvreux MV, Ben-Shlomo A, Araki T, Barrett R, Workman M, Wawrowsky K, Ljubimov VA et al. Growth hormone is permissive for neoplastic colon growth. PNAS 2016113 E3250-E3259. (https://doi.org/10.1073/pnas.1600561113)

45 Chesnokova V, Zonis S, Barrett R, Kameda H, Wawrowsky K, BenShlomo A, Yamamoto M, Gleeson J, Bresee C, Gorbunova V et al. Excess growth hormone suppresses DNA damage repair in epithelial cells. JCI Insight 20194 e125762. (https://doi.org/10.1172/jci. insight.125762)

46 Chesnokova V, Zonis S, Barrett RJ, Gleeson JP \& Melmed S. Growth hormone induces colon DNA damage independent of IGF-1. Endocrinology 2019160 1439-1447. (https://doi.org/10.1210/ en.2019-00132)

47 Ma J, Pollak MN, Giovannucci E, Chan JM, Tao Y, Hennekens CH \& Stampfer MJ. Prospective study of colorectal cancer risk in men and plasma levels of insulin-like growth factor (IGF)-I and IGF-binding protein-3. Journal of the National Cancer Institute 199991 620-625. (https://doi.org/10.1093/jnci/91.7.620)

48 Giovannucci E, Pollak MN, Platz EA, Willett WC, Stampfer MJ, Majeed N, Colditz GA, Speizer FE \& Hankinson SE. A prospective study of plasma insulin-like growth factor-1 and binding protein-3 and risk of colorectal neoplasia in women. Cancer Epidemiology, Biomarkers and Prevention 20009 345-349.

49 Kaaks R, Toniolo P, Akhmedkhanov A, Lukanova A, Biessy C, Dechaud H, Rinaldi S, Zeleniuch-Jacquotte A, Shore RE \& Riboli E. Serum C-peptide, insulin-like growth factor (IGF)-I, IGF-binding proteins, and colorectal cancer risk in women. Journal of the National Cancer Institute 200092 1592-1600. (https://doi.org/10.1093/ jnci/92.19.1592)

50 Juul A, Pedersen SA, Sørensen S, Winkler K, Jørgensen JO, Christiansen JS \& Skakkebaek NE. Growth hormone (GH) treatment increases serum insulin-like growth factor binding protein-3, bone 
isoenzyme alkaline phosphatase and forearm bone mineral content in young adults with GH deficiency of childhood onset. European Journal of Endocrinology 1994131 41-49. (https://doi.org/10.1530/ eje.0.1310041)

51 Ghigo E, Aimaretti G, Maccario M, Fanciulli G, Arvat E, Minuto F, Giordano G, Delitala G \& Camanni F. Dose-response study of GH effects on circulating IGF-I and IGFBP-3 levels in healthy young men and women. American Journal of Physiology 1999276 E1009-E1013. (https://doi.org/10.1152/ajpendo.1999.276.6.E1009)

52 Giovannucci E \& Pollak M. Risk of cancer after growth-hormone treatment. Lancet 2002360 268-269. (https://doi.org/10.1016/S01406736(02)09561-2)

53 Rokkas T, Pistiolas D, Sechopoulos P, Margantinis G \& Koukoulis G. Risk of colorectal neoplasm in patients with acromegaly: a metaanalysis. World Journal of Gastroenterology 200814 3484-3489. (https://doi.org/10.3748/wjg.14.3484)

54 Terzolo M, Reimondo G, Gasperi M, Cozzi R, Pivonello R, Vitale G, Scillitani A, Attanasio R, Cecconi E, Daffara F et al. Colonoscopic screening and follow-up in patients with acromegaly: a multicenter study in Italy. Journal of Clinical Endocrinology and Metabolism 2005 90 84-90. (https://doi.org/10.1210/jc.2004-0240)

55 MUSTACCHI P \& SHIMKIN MB. Occurrence of cancer in acromegaly and in hypopituitarism. Cancer 195710 100-104. (https://doi.org/10.1002/1097-0142(195701/02)10:1<100::aidcncr2820100113>3.0.co;2-v)

56 Wright AD, Hill DM, Lowy C \& Fraser TR. Mortality in acromegaly. Quarterly Journal of Medicine 197039 1-16.

57 Bengtsson BA, Edén S, Ernest I, Odén A \& Sjögren B. Epidemiology and long-term survival in acromegaly. A study of 166 cases diagnosed between 1955 and 1984. Acta Medica Scandinavica 1988223 327-335. (https://doi.org/10.1111/j.0954-6820.1988. tb15881.x)

58 Nabarro JD. Acromegaly. Clinical Endocrinology 198726 481-512. (https://doi.org/10.1111/j.1365-2265.1987.tb00805.x)

59 Pines A, Rozen P, Ron E \& Gilat T. Gastrointestinal tumors in acromegalic patients. American Journal of Gastroenterology $1985 \mathbf{8 0}$ 266-269.

60 Barzilay J, Heatley GJ \& Cushing GW. Benign and malignant tumors in patients with acromegaly. Archives of Internal Medicine 1991151 1629-1632.

61 Rajasoorya C, Holdaway IM, Wrightson P, Scott DJ \& Ibbertson HK. Determinants of clinical outcome and survival in acromegaly. Clinical Endocrinology 199441 95-102. (https://doi. org/10.1111/j.1365-2265.1994.tb03789.x)

62 Cheung NW \& Boyages SC. Increased incidence of neoplasia in females with acromegaly. Clinical Endocrinology 199747 323-327. (https://doi.org/10.1046/j.1365-2265.1997.2561053.x)

63 Orme SM, McNally RJ, Cartwright RA \& Belchetz PE. Mortality and cancer incidence in acromegaly: a retrospective cohort study. United Kingdom Acromegaly Study Group. Journal of Clinical Endocrinology and Metabolism 199883 2730-2734. (https://doi.org/10.1210/ jcem.83.8.5007)

64 Popovic V, Damjanovic S, Micic D, Nesovic M, Djurovic M, Petakov M, Obradovic S, Zoric S, Simic M, Penezic Z et al. Increased incidence of neoplasia in patients with pituitary adenomas. The Pituitary Study Group. Clinical Endocrinology 199849 441-445. (https://doi.org/10.1046/j.1365-2265.1998.00536.x)

65 Higuchi Y, Saeki N, Iuchi T, Uchino Y, Tatsuno I, Uchida D, Tanaka T, Noguchi Y, Nakamura S, Yasuda T et al. Incidence of malignant tumors in patients with acromegaly. Endocrine Journal 200047 (Supplement) S57-S60. (https://doi.org/10.1507/endocrj.47. supplmarch_557)

66 Holdaway IM, Rajasoorya RC \& Gamble GD. Factors influencing mortality in acromegaly. Journal of Clinical Endocrinology and Metabolism 200489 667-674. (https://doi.org/10.1210/jc.2003031199)
67 Ayuk J, Clayton RN, Holder G, Sheppard MC, Stewart PM \& Bates AS. Growth hormone and pituitary radiotherapy, but not serum insulin-like growth factor-I concentrations, predict excess mortality in patients with acromegaly. Journal of Clinical Endocrinology and Metabolism 200489 1613-1617. (https://doi.org/10.1210/jc.2003031584)

68 Kurimoto M, Fukuda I, Hizuka N \& Takano K. The prevalence of benign and malignant tumors in patients with acromegaly at a single institute. Endocrine Journal 200855 67-71. (https://doi.org/10.1507/ endocrj.k07e-010)

69 Gullu BE, Celik O, Gazioglu N \& Kadioglu P. Thyroid cancer is the most common cancer associated with acromegaly. Pituitary 201013 242-248. (https://doi.org/10.1007/s11102-010-0224-9)

70 Bałdys-Waligórska A, Krzentowska A, Gołkowski F, Sokołowski G \& Hubalewska-Dydejczyk A. The prevalence of benign and malignant neoplasms in acromegalic patients. Endokrynologia Polska 201061 29-34.

71 Kauppinen-Mäkelin R, Sane T, Reunanen A, Välimäki MJ, Niskanen L, Markkanen H, Löyttyniemi E, Ebeling T, Jaatinen P, Laine $\mathrm{H}$ et al. A nationwide survey of mortality in acromegaly. Journal of Clinical Endocrinology and Metabolism 200590 4081-4086. (https://doi. org/10.1210/jc.2004-1381)

72 Arosio M, Reimondo G, Malchiodi E, Berchialla P, Borraccino A, De Marinis L, Pivonello R, Grottoli S, Losa M, Cannavò S et al. Predictors of morbidity and mortality in acromegaly: an Italian survey. European Journal of Endocrinology 2012167 189-198. (https://doi.org/10.1530/ EJE-12-0084)

73 Dagdelen S, Cinar N \& Erbas T. Increased thyroid cancer risk in acromegaly. Pituitary 201417 299-306. (https://doi.org/10.1007/ s11102-013-0501-5)

74 Mercado M, Gonzalez B, Vargas G, Ramirez C, de los Monteros AL, Sosa E, Jervis P, Roldan P, Mendoza V, López-Félix B et al. Successful mortality reduction and control of comorbidities in patients with acromegaly followed at a highly specialized multidisciplinary clinic. Journal of Clinical Endocrinology and Metabolism 201499 4438-4446. (https://doi.org/10.1210/jc.2014-2670)

75 Dal J, Feldt-Rasmussen U, Andersen M, Kristensen LØ, Laurberg P, Pedersen L, Dekkers OM, Sørensen HT \& Jørgensen JO. Acromegaly incidence, prevalence, complications and long-term prognosis: a nationwide cohort study. European Journal of Endocrinology 2016175 181-190. (https://doi.org/10.1530/EJE-16-0117)

76 Maione L, Brue T, Beckers A, Delemer B, Petrossians P, BorsonChazot F, Chabre O, François P, Bertherat J, Cortet-Rudelli C et al. Changes in the management and comorbidities of acromegaly over three decades: the French Acromegaly Registry. European Journal of Endocrinology 2017176 645-655. (https://doi.org/10.1530/EJE-161064)

77 Esposito D, Ragnarsson O, Granfeldt D, Marlow T, Johannsson G \& Olsson DS. Decreasing mortality and changes in treatment patterns in patients with acromegaly from a nationwide study. European Journal of Endocrinology 2018178 459-469. (https://doi.org/10.1530/ EJE-18-0015)

78 Jenkins PJ, Fairclough PD, Richards T, Lowe DG, Monson J, Grossman A, Wass JA \& Besser M. Acromegaly, colonic polyps and carcinoma. Clinical Endocrinology 199747 17-22. (https://doi. org/10.1046/j.1365-2265.1997.1911029.x)

79 Dworakowska D, Gueorguiev M, Kelly P, Monson JP, Besser GM, Chew SL, Akker SA, Drake WM, Fairclough PD, Grossman AB et al. Repeated colonoscopic screening of patients with acromegaly: 15-year experience identifies those at risk of new colonic neoplasia and allows for effective screening guidelines. European Journal of Endocrinology 2010163 21-28. (https://doi.org/10.1530/EJE-09-1080)

80 Katznelson L, Atkinson JL, Cook DM, Ezzat SZ, Hamrahian AH, Miller KK \& American Association of Clinical Endocrinologists. American Association of Clinical Endocrinologists medical guidelines for clinical practice for the diagnosis and treatment of acromegaly 
- 2011 update. Endocrine Practice 201117 (Supplement 4) 1-44. (https://doi.org/10.4158/ep.17.s4.1)

81 Melmed S, Casanueva FF, Klibanski A, Bronstein MD, Chanson P, Lamberts SW, Strasburger CJ, Wass JA \& Giustina A. A consensus on the diagnosis and treatment of acromegaly complications. Pituitary 201316 294-302. (https://doi.org/10.1007/s11102-012-0420-x)

82 Løberg M, Kalager M, Holme Ø, Hoff G, Adami HO \& Bretthauer M. Long-term colorectal-cancer mortality after adenoma removal. New England Journal of Medicine 2014371 799-807. (https://doi. org/10.1056/NEJMoa1315870)

83 Wassenaar MJ, Cazemier M, Biermasz NR, Pereira AM, Roelfsema F, Smit JW, Hommes DW, Felt-Bersma RJ \& Romijn JA. Acromegaly is associated with an increased prevalence of colonic diverticula: a casecontrol study. Journal of Clinical Endocrinology and Metabolism 2010 95 2073-2079. (https://doi.org/10.1210/jc.2009-1714)

84 Jenkins PJ. Acromegaly and cancer. Hormone Research 200462 (Supplement 1) 108-115. (https://doi.org/10.1159/000080768)

85 Jenkins PJ. Cancers associated with acromegaly. Neuroendocrinology 200683 218-223. (https://doi.org/10.1159/000095531)

86 Dworakowska D \& Grossman AB. Colonic cancer and acromegaly. Frontiers in Endocrinology 201910 390. (https://doi.org/10.3389/ fendo.2019.00390)

87 Tirosh A \& Shimon I. Complications of acromegaly: thyroid and colon. Pituitary 201720 70-75. (https://doi.org/10.1007/s11102-016-0744-z)

88 Gasperi M, Martino E, Manetti L, Arosio M, Porretti S, Faglia G, Mariotti S, Colao AM, Lombardi G, Baldelli R et al. Prevalence of thyroid diseases in patients with acromegaly: results of an Italian multi-center study. Journal of Endocrinological Investigation 200225 240-245. (https://doi.org/10.1007/BF03343997)

89 Siegel G \& Tomer Y. Is there an association between acromegaly and thyroid carcinoma? A critical review of the literature. Endocrine Research 200531 51-58. (https://doi. org/10.1080/07435800500229177)

90 Tita P, Ambrosio MR, Scollo C, Carta A, Gangemi P, Bondanelli M, Vigneri R, degli Uberti EC \& Pezzino V. High prevalence of differentiated thyroid carcinoma in acromegaly. Clinical Endocrinology 200563 161-167. (https://doi.org/10.1111/j.13652265.2005.02316.x)

91 Kaldrymidis D, Papadakis G, Tsakonas G, Kaldrymidis P, Flaskas T, Seretis A, Pantazi E, Kostoglou-Athanassiou I, Peppa M, Roussou P et al. High incidence of thyroid cancer among patients with acromegaly. Journal of B.U.ON. 201621 989-993. (https://doi. org/10.1530/endoabs.41.EP890)

92 Reverter JL, Fajardo C, Resmini E, Salinas I, Mora M, Llatjos M, Sesmilo G, Rius F, Halperin I, Webb SM et al. Benign and malignant nodular thyroid disease in acromegaly. Is a routine thyroid ultrasound evaluation advisable? PLOS ONE 20149 e104174. (https:// doi.org/10.1371/journal.pone.0104174)

93 Ferlay J, Autier P, Boniol M, Heanue M, Colombet M \& Boyle P. Estimates of the cancer incidence and mortality in Europe in 2006. Annals of Oncology 200718 581-592. (https://doi.org/10.1093/ annonc/mdl498)
94 Rego-Iraeta A, Perez-Mendez LF, Mantinan B \& Garcia-Mayor RV. Time trends for thyroid cancer in northwestern Spain: true rise in the incidence of micro and larger forms of papillary thyroid carcinoma. Thyroid 200919 333-340. (https://doi.org/10.1089/ thy.2008.0210)

95 Davies L \& Welch HG. Increasing incidence of thyroid cancer in the United States, 1973-2002. JAMA 2006295 2164-2167. (https://doi. org/10.1001/jama.295.18.2164)

96 Marchisotti FG, Umeda LM, Zach PL, Saldanha MD, First OS \& Liberman B. Acromegaly and thyroid disease: prevalence of thyroid cancer. Arquivos Brasileiros de Endocrinologia e Metabologia 200549 843-849. (https://doi.org/10.1590/s0004-27302005000500027)

97 Parolin M, Dassie F, Russo L, Mazzocut S, Ferrata M, De Carlo E, Mioni R, Fallo F, Vettor R, Martini C et al. Guidelines versus real life practice: the case of colonoscopy in acromegaly. Pituitary $2018 \mathbf{2 1}$ 16-24. (https://doi.org/10.1007/s11102-017-0841-7)

98 Colao A, Pivonello R, Auriemma RS, Galdiero M, Ferone D, Minuto F, Marzullo P \& Lombardi G. The association of fasting insulin concentrations and colonic neoplasms in acromegaly: a colonoscopybased study in 210 patients. Journal of Clinical Endocrinology and Metabolism 200792 3854-3860. (https://doi.org/10.1210/jc.20062551)

99 Lois K, Bukowczan J, Perros P, Jones S, Gunn M \& James RA. The role of colonoscopic screening in acromegaly revisited: review of current literature and practice guidelines. Pituitary 201518 568-574. (https:// doi.org/10.1007/s11102-014-0586-5)

100 Renehan AG, O'Dwyer ST \& Shalet SM. Colorectal neoplasia in acromegaly: the reported increased prevalence is overestimated. Gut 200046 440-441. (https://doi.org/10.1136/gut.46.3.440)

101 Renehan AG, O’Dwyer ST \& Shalet SM. Guidelines for colonoscopic screening in acromegaly are inconsistent with those for other high risk groups. Gut 200352 1071-1072; author reply 1072. (https://doi. org/10.1136/gut.52.7.1071-a)

102 Renehan AG \& Shalet SM. Acromegaly and colorectal cancer: risk assessment should be based on population-based studies. Journal of Clinical Endocrinology and Metabolism 200287 1909; author reply 1909. (https://doi.org/10.1210/jcem.87.4.8369)

103 Bogazzi F, Cosci C, Sardella C, Costa A, Manetti L, Gasperi M, Rossi G, Bartalena L \& Martino E. Identification of acromegalic patients at risk of developing colonic adenomas. Journal of Clinical Endocrinology and Metabolism 200691 1351-1356. (https://doi. org/10.1210/jc.2005-2500)

104 Cairns SR, Scholefield JH, Steele RJ, Dunlop MG, Thomas HJ, Evans GD, Eaden JA, Rutter MD, Atkin WP, Saunders BP et al. Guidelines for colorectal cancer screening and surveillance in moderate and high risk groups (update from 2002). Gut 201059 666-689. (https://doi.org/10.1136/gut.2009.179804)

105 Melmed S. Acromegaly and cancer: not a problem? Journal of Clinical Endocrinology and Metabolism 200186 2929-2934. (https://doi. org/10.1210/jcem.86.7.7635)

106 Perry I, Stewart PM \& Kane K. Colorectal screening guidelines in acromegaly. Gut $2003 \mathbf{5 2}$ 1387; author reply 1387.

Received 20 December 2019

Revised version received 10 June 2020

Accepted 6 July 2020 